\title{
OPEN Supercapacitor performance of porous nickel cobaltite nanosheets
}

\begin{abstract}
Xin Chen $^{1}$, Rui Xie ${ }^{2}$, Hui Li ${ }^{3}$, F. Jaber ${ }^{4}$, F. Musharavati ${ }^{5}$, E. Zalnezhad ${ }^{6}$, S. Bae ${ }^{7 凶}$, K. S. Hui ${ }^{8} \&$ K. N. Hui

In this work, nickel cobaltite $\left(\mathrm{NiCO}_{2} \mathrm{O}_{4}\right)$ nanosheets with a porous structure were fabricated on nickel foam as a working electrode for supercapacitor applications. The nanosheets were fabricated by electrochemical deposition of nickel-cobalt hydroxide on the nickel foam substrate at ambient temperature in a three-electrode cell followed by annealing at $300^{\circ} \mathrm{C}$ to transform the coating into a porous $\mathrm{NiCO}_{2} \mathrm{O}_{4}$ nanosheet. Field emission scanning electron microscopy and transmission electron microscopy revealed a three-dimensional mesoporous structure, which facilitates ion transport and electronic conduction for fast redox reactions. For one cycle, the $\mathrm{NiCO}_{2} \mathrm{O}_{4}$ electrodeposited nickel foam has a high specific capacitance $\left(1734.9 \mathrm{~F} \mathrm{~g}^{-1}\right.$ ) at a current density (CD) of $2 \mathrm{~A} \mathrm{~g}^{-1}$. The electrode capacitance decreased by only approximately $12.7 \%$ after 3500 cycles at a CD of $30 \mathrm{~A} \mathrm{~g}^{-1}$. Moreover, a solid-state asymmetric supercapacitor (ASC) was built utilising the $\mathrm{NiCO}_{2} \mathrm{O}_{4}$ nanosheets, carbon nanotubes, and a polyvinyl alcohol-potassium hydroxide gel as the anode, cathode, and solid-state electrolyte, respectively. The ASC displayed great electrochemical properties with a $42.25 \mathrm{~W} \mathrm{~h} \mathrm{~kg}^{-1}$ energy density at a power density of $298.79 \mathrm{~W} \mathrm{~kg}^{-1}$.
\end{abstract}

Due to rapidly increasing logical pollution, fossil fuel depletion, and the fast growth of the worldwide economy, it is vital to develop clean, sustainable, and efficient energy resources, along with new technologies for energy conversion and storage ${ }^{1-5}$. In recent years, ultracapacitors, or electrochemical supercapacitors (ESs), have generated substantial interest, owing mostly to their long lifecycles, high power density, and ability to bridge the power/energy gap in conventional batteries/fuel cells and dielectric capacitors because of their high energy storage capacity and high power output ${ }^{6,7}$.

Lately, many researches have concentrated on binary metal oxides. Their outstanding specific capacity and great electrical conductivity are better than single component oxides due to their attainable oxidation states for multiple redox reaction ${ }^{8}$. Furthermore, binary metal oxides have many other benefits, such as relative abundance, low cost, and environmental friendliness ${ }^{9}$. In recent years, researches have shown that binary metal oxides, such as nickel cobaltite $\left(\mathrm{NiCo}_{2} \mathrm{O}_{4}\right), \mathrm{ZnCo}_{2} \mathrm{O}_{4}$, and $\mathrm{Zn}_{2} \mathrm{SnO}_{4}$ are favourable materials that show improved electrochemical performance. Moreover, they are scalable replacements owning to their ample surface active sites, high electrical conductivity, strong permeability, and attainable oxidation states. Thus, many works have been performed to synthesize dissimilar bimetallic oxide nanomaterials for supercapacitor applications with great rate capabilities. The binary metal oxide $\mathrm{NiCo}_{2} \mathrm{O}_{4}$ was recently studied for use as an electrode owing to its electrochemical activity, stability, and higher electronic conductivity compared to single metal oxides ${ }^{10-13} \cdot \mathrm{NiCo}_{2} \mathrm{O}_{4}$ has a structure similar to $\mathrm{Co}_{3} \mathrm{O}_{4}$ (spinel structure), and both the $\mathrm{Co}$ and $\mathrm{Ni}$ ion have a mixed oxidation state ${ }^{14,15}$. The electrical conductivity of $\mathrm{NiCo}_{2} \mathrm{O}_{4}$ is more than twice that of the Co or Ni oxide alone because the replacement of Co with $\mathrm{Ni}$ brings additional electrons into the $3 \mathrm{~d}$ orbital, which subtly changes the density of electrons in the crystal structure. The $\mathrm{NiCo}_{2} \mathrm{O}_{4}$ working potential window is often very slim, near $0-0.5 \mathrm{~V}$, in comparison with alkaline

\footnotetext{
${ }^{1}$ Department of Mechanical Convergence Engineering, Hanyang University, 222 Wangsimni-ro, Seongdong-gu, Seoul 04763, South Korea. ${ }^{2}$ Department of Electronic Information, Shandong Xiandai University, Jinan 250000, People's Republic of China. ${ }^{3}$ Department of Chemical Engineering, Hanyang University, 222 Wangsimni-ro, Seongdong-gu, Seoul 04763, South Korea. 'Department of Biomedical Engineering, Ajman University, 2758, Ajman, UAE. ${ }^{5}$ Department of Mechanical and Industrial Engineering, College of Engineering, Qatar University, 2713, Doha, Qatar. ${ }^{6}$ Department of Chemical and Biomedical Engineering, University of Texas At San Antonio, San Antonio, TX, USA. ${ }^{7}$ Department of Architectural Engineering, Hanyang University, Seoul 04763, Korea. ${ }^{8}$ School of Engineering, University of East Anglia, Norwich NR4 7TJ, UK. ${ }^{9}$ Joint Key Laboratory of the Ministry of Education, Institute of Applied Physics and Materials Engineering, University of Macau, Avenida da Universidade, Taipa, Macau SAR 999078, China. ${ }^{\square}$ email: erfan.zalnezhad@utsa.edu; sbae@hanyang.ac.kr
} 


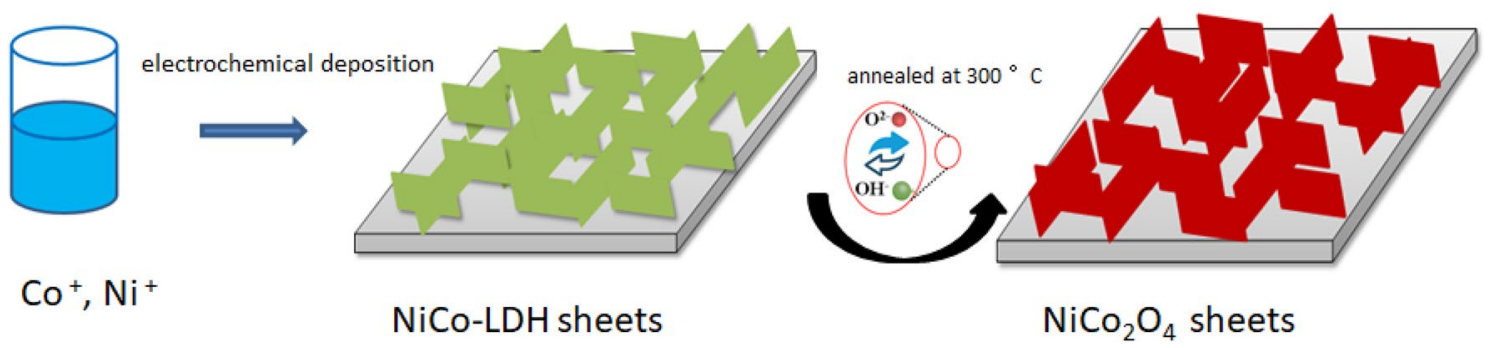

Figure 1. Schematic illustration of porous $\mathrm{NiCo}_{2} \mathrm{O}_{4}$ sheets synthesis.

solutions $(\mathrm{Ag} / \mathrm{AgCl})^{16-19}$. It has been proved that the introduction of graphene can effectively enhance the total capacitance and stability, primarily because graphene can withstand the basic structures of polyaniline and evade mechanical deformation in the redox process ${ }^{20}$. Therefore, ternary composites with carbon nanomaterials, using transition metal oxides and polymers, have been studied and showed an enhancement in the electrochemical performance that open a new fabrication pathway for next generation high-performance electrochemical electrodes ${ }^{21}$. Ternary $\mathrm{CuCo}_{2} \mathrm{~S}_{4}$ is well known as an electrode material for electrochemical capacitors because of its synergistic effects, high conductivity, and low cost. The supercapacitive performance of $\mathrm{CuCo}_{2} \mathrm{~S}_{4}$ electrodes for electrochemical capacitors was investigated by Xu et al. In their study, thin layers of $\mathrm{CuCo}_{2} \mathrm{~S}_{4}$ were deposited on conductive substrates, and the results showed better properties than single crystal $\mathrm{CuCo}_{2} \mathrm{~S}_{4}{ }^{22}$.

Electrodeposition has been utilised for different applications, such as microelectronics and energy conversion. Because of the need for enhanced performance and device miniaturization, nuanced control of the growth process is needed; electrochemical deposition is a technique that can fulfil those requirements ${ }^{23}$.

Chen et al. successfully deposited $\mathrm{Ni}-\mathrm{Co}-\mathrm{S}$ nanosheet arrays on carbon fibres through one-step electrodeposition of the ternary sulfides to provide an effective and facile approach for large scale applications, which was a significant advantage compared to other multistep synthesis techniques. They found that the Ni-Co-S-4 interconnected nanosheet exhibits the best electrochemical performance as a supercapacitor electrode ${ }^{24}$.

One effective method of enlarging the potential window of the $\mathrm{NiCo}_{2} \mathrm{O}_{4}$ electrode to attain a high energy density is the utilisation of asymmetric devices ${ }^{16,25-27}$. For example, Yedluri et al. fabricated chain-like $\mathrm{NiCo}_{2} \mathrm{O}_{4} /$ $\mathrm{NiCo}_{2} \mathrm{O}_{4}$ nanofile arrays using a facile hydrothermal and thermal decomposition approach and reported a specific capacitance of $2312 \mathrm{~F} \mathrm{~g}^{-1}$ at a current density (CD) of $2 \mathrm{~mA} \mathrm{~cm}^{-228}$. They also studied the electrochemical performance of $\mathrm{NiCo}_{2} \mathrm{O}_{4} @ \mathrm{NiCo}_{2} \mathrm{O}_{4}$ composite nanoplates and $\mathrm{NiCo}_{2} \mathrm{O}_{4}$ nanoplates decorated with $\mathrm{NiMoO}_{4}$ honeycombs for high performance supercapacitor applications $s^{29,30}$. Herein, we developed a solid asymmetric supercapacitor with a pre-synthesised $\mathrm{NiCo}_{2} \mathrm{O}_{4}$ mesoporous electrode without binders, where a nickel foam (with high conductivity) was selected as a current collector, and the $\mathrm{NiCo}_{2} \mathrm{O}_{4}$ provided a large surface area along with a unique mesoporous nanostructure. Our sample delivered a specific capacitance of $1734.9 \mathrm{~F} \mathrm{~g}^{-1}$ at a $2 \mathrm{~A} \mathrm{~g}^{-1} \mathrm{CD}$ with a retention rate of $87.3 \%$ at a $30 \mathrm{~A} \mathrm{~g}^{-1} \mathrm{CD}$ for 3500 cycles. Furthermore, the application of a $\mathrm{NiCo}_{2} \mathrm{O}_{4}$-based binder-free electrode to a solid asymmetric supercapacitor resulted in a $42.25 \mathrm{~W} \mathrm{~h} \mathrm{~kg}^{-1}$ energy density at a power density of $298.79 \mathrm{~W} \mathrm{~kg}^{-1}$ (Fig. 1).

\section{Results and discussion}

Figure 2 depicts SEM images of $\mathrm{NiCo}-\mathrm{LDH}$ and $\mathrm{NiCo}_{2} \mathrm{O}_{4}$. The images show that a smooth, uniform array of $\mathrm{NiCo}_{2} \mathrm{O}_{4}$ nanosheets is grown on the nickel foam surface, and the nanosheets are interlaced to form a mesoporous structure. Figure 2 (a) shows that the NiCo-LDH possesses an interconnected nanosheet microstructure. Figure 2(b, c) shows SEM images of $\mathrm{NiCo}_{2} \mathrm{O}_{4}$. These nanosheets, which are several hundred nanometers in size, have a porous structure that is intercrossed, which contains electroactive surface sites and plentiful vacancies ${ }^{31-33}$.

The products were further examined by X-ray diffraction (XRD) analysis. Figure 3 depicts the XRD pattern of the $\mathrm{NiCo}_{2} \mathrm{O}_{4}$ nanosheets deposited on the $\mathrm{Ni}$ foam. The peaks (from the (111), (200), and (220) planes, respectively) at $44.7^{\circ}, 52.1^{\circ}$, and $76.5^{\circ}$, denoted by asterisks, are created from the nickel foam. The peaks at $18.9^{\circ}$, $36.6^{\circ}, 59.1^{\circ}$, and $64.9^{\circ}$ can be clearly observed and are well indexed to the (111), (311), (511), and (440) planes,

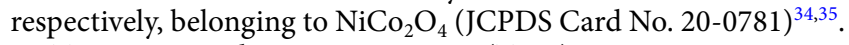

Transmission electron microscopy (TEM) measurements were performed to further investigate the structure of the synthesised $\mathrm{NiCo}_{2} \mathrm{O}_{4}$ nanosheets, as shown in Fig. 4. Figure $4(\mathrm{a}, \mathrm{b})$ shows a $\mathrm{NiCo}_{2} \mathrm{O}_{4}$ nanosheet with a folding, silk-like morphology and transparent features, indicating its interconnected nature. Due to the significant difference between the lateral size and thickness, bending and crumpling are clearly observed. The spacing between adjacent fringes is $\sim 0.29 \mathrm{~nm}$, which is close to the theoretical interplane spacing of spinel $\mathrm{NiCo}_{2} \mathrm{O}_{4}(311)$ planes. Thus, the interconnected nanosheets are composed of 1-3 layers of $\mathrm{NiCo}_{2} \mathrm{O}_{4}$ atomic sheets. The selected area electron diffraction (SAED) pattern (Fig. 4 (c)) presents distinct diffraction rings, indicating polycrystalline characteristics. Furthermore, several interparticle mesopores, with sizes ranging from 1 to $3 \mathrm{~nm}$, in these interconnected nanosheets can be evidently seen (Fig. $4(\mathrm{a}, \mathrm{b})$ ). It is believed that the mesoporous structures in nanosheets are imperative in facilitating the electrolytes' mass transport within the electrodes for double-layer 

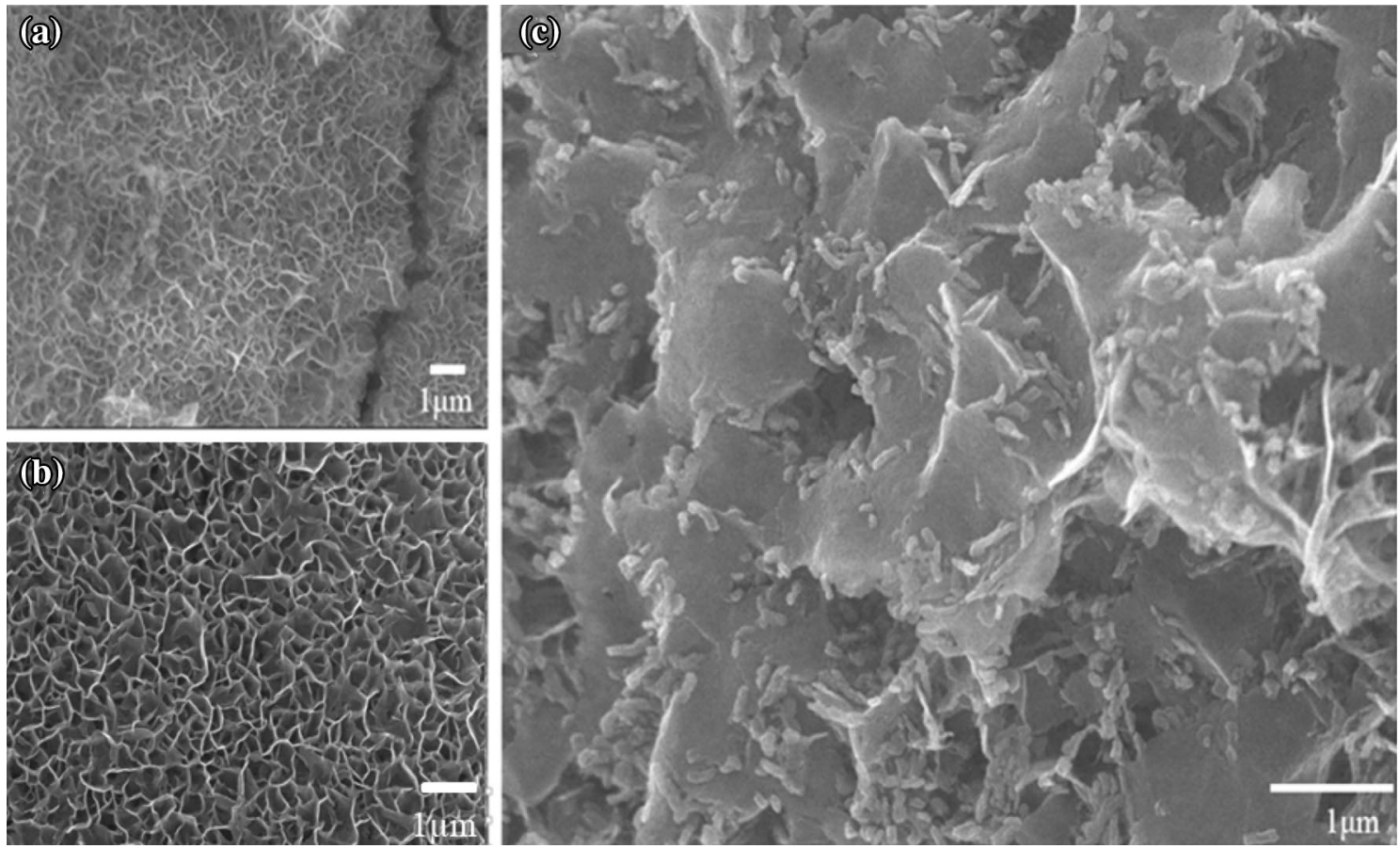

Figure 2. FESEM images of (a) Ni foam covered by the bimetallic (Ni, Co) hydroxide precursor, and (b, c) the derived $\mathrm{NiCo}_{2} \mathrm{O}_{4} 1$ interconnected sheets.

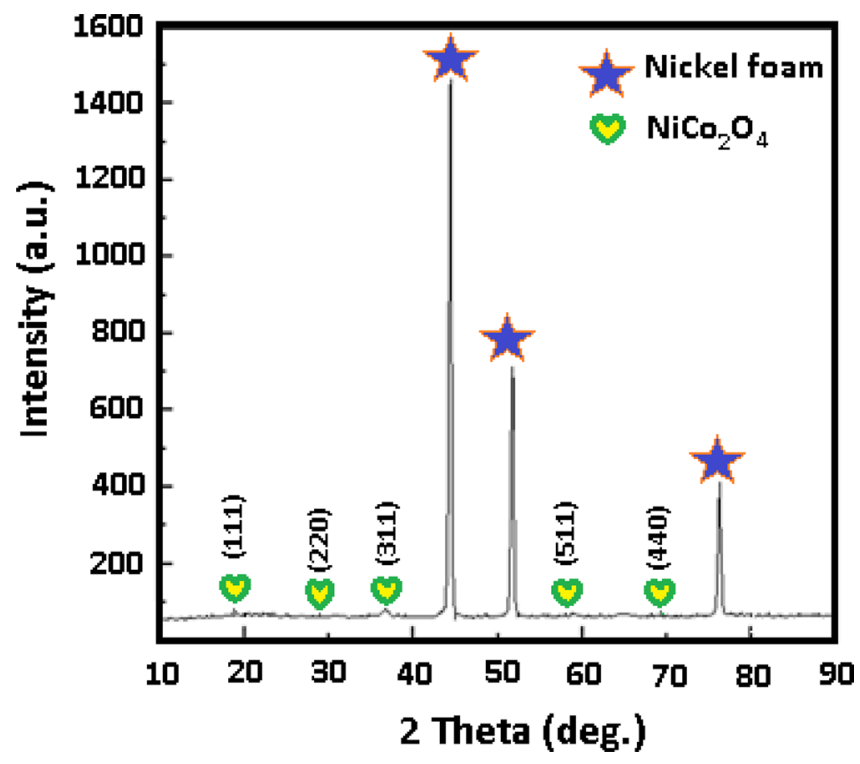

Figure 3. XRD pattern of $\mathrm{NiCo}_{2} \mathrm{O}_{4}$.

charging/discharging and quick redox reactions ${ }^{8}$. The porous structure also significantly increases the contact area of electrolyte/electrode, and consequently enhances the electrochemical performance ${ }^{9-15}$. To show the advantages of this architecture, the interconnected mesoporous $\mathrm{NiCo}_{2} \mathrm{O}_{4}$ nanosheets with hybrid structure fabricated on $\mathrm{Ni}$ foam was directly applied as an electrode for a supercapacitor. Figure 4(d) show the energy dispersive X-ray spectroscopy (EDS) analysis of the $\mathrm{NiCo}_{2} \mathrm{O}_{4}$ sample; $\mathrm{Co}, \mathrm{Ni}$, and $\mathrm{O}$ are detected. This result confirms the chemical composition of the $\mathrm{NiCo}_{2} \mathrm{O}_{4}$ structure.

$\mathrm{X}$-ray photoelectron spectroscopy (XPS) tests, along with the corresponding fitting results are shown in Fig. 5. Gaussian fitting method was used to best fit the Ni $2 p$ and Co $2 p$ (with two spin-orbit doublets for each), characteristic of $\mathrm{Ni}^{2+}$ and $\mathrm{Ni}^{3+}$ and $\mathrm{Co}^{2+}$ and $\mathrm{Co}^{3+}$, respectively and two shake-up satellite (indicated as "Sat.") for both $\mathrm{Ni} 2 \mathrm{p}$ and $\mathrm{Co} 2$. These data show that the surface of the as-prepared $\mathrm{NiCo}_{2} \mathrm{O}_{4}$ contains $\mathrm{Co}^{2+}, \mathrm{Co}^{3+}, \mathrm{Ni}^{2+}$, and $\mathrm{Ni}^{3+}$. where the atomic ratio of Co to Ni elements is $c a$. 2.2:1, which is close to that in the precursor electrolyte. 

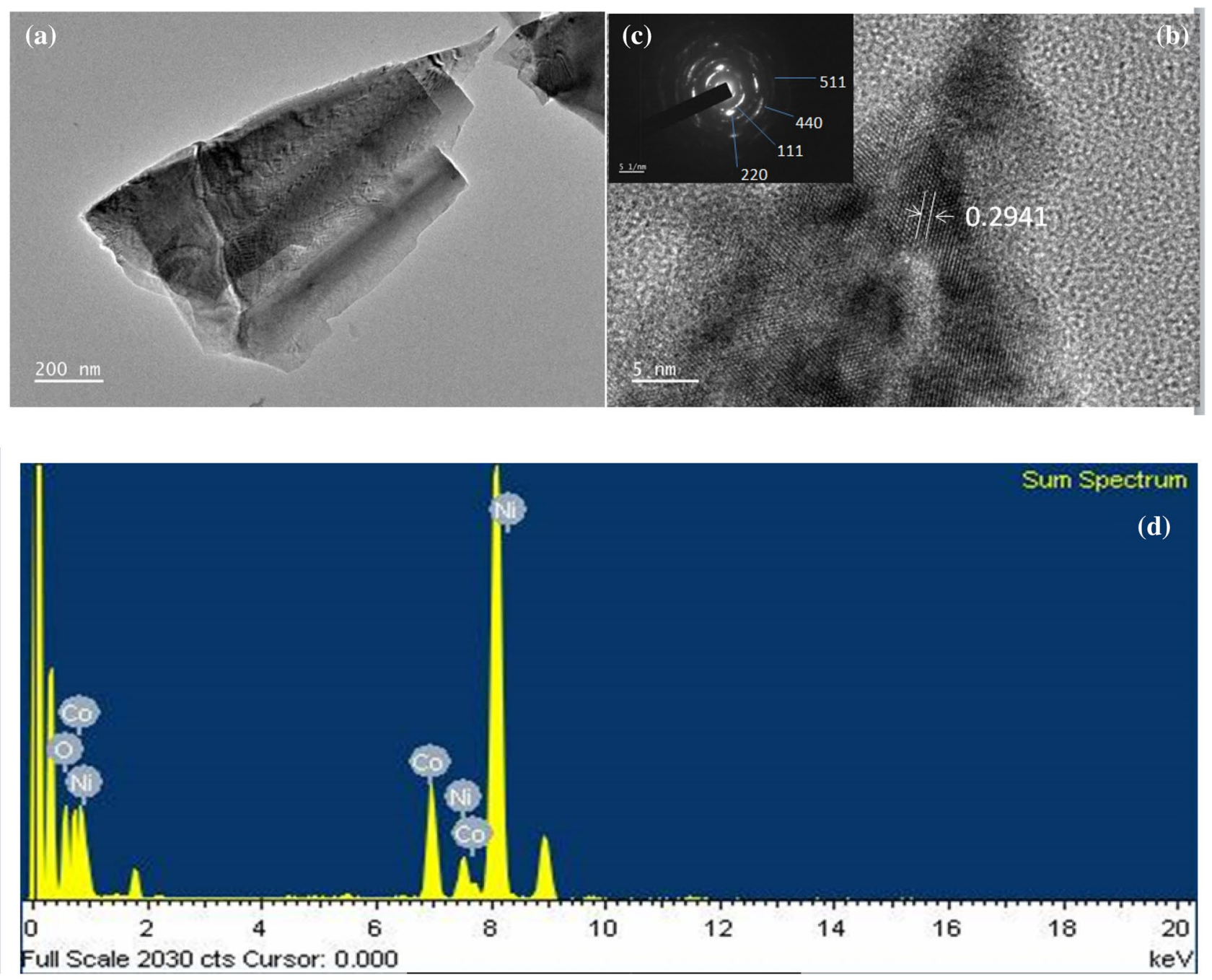

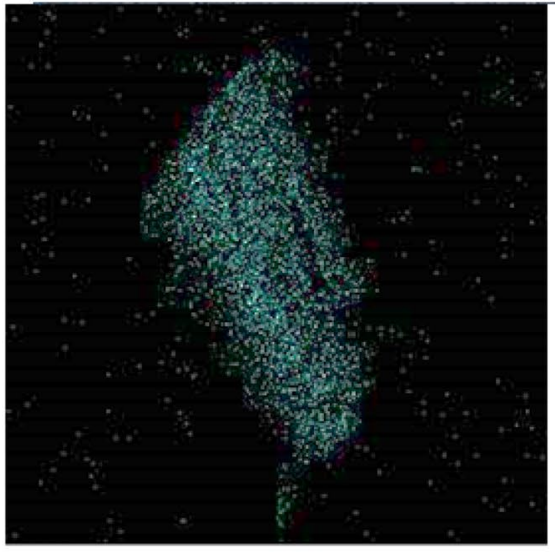

CoKa1

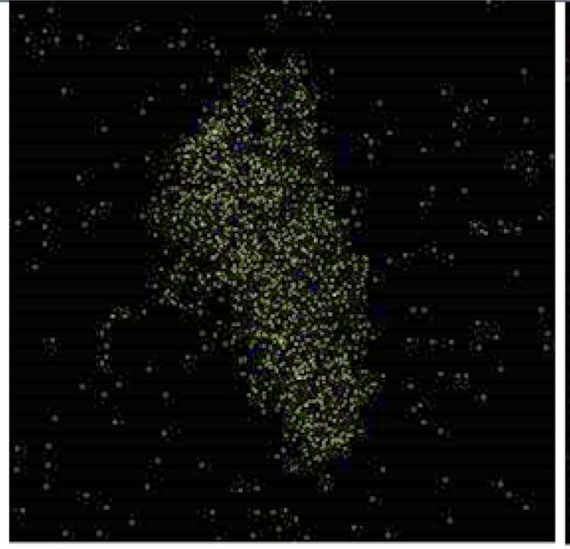

Ni Ka1

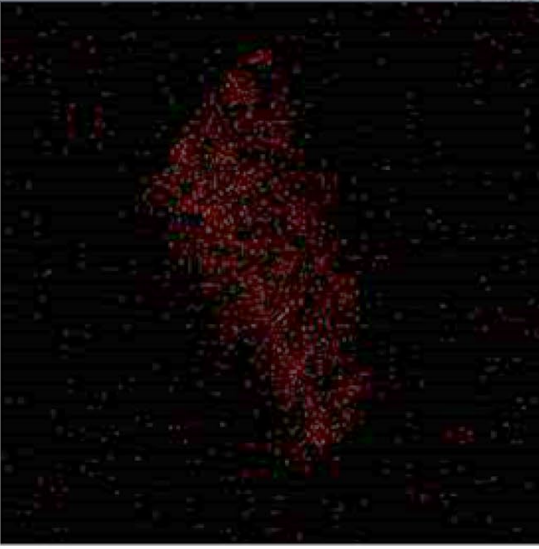

OKa1

Figure 4. (a) TEM image and (b) HRTEM image of an individual $\mathrm{NiCo}_{2} \mathrm{O}_{4}$ nanosheet, along with (c) the SAED pattern (inset), and (d) the corresponding EDS mapping results.

Nitrogen adsorption/desorption measurements were utilised to examine the porosity and BET surface area and of samples. All the $\mathrm{N}_{2}$ adsorption/desorption isotherms in Fig. 6 exhibit a typical IV isotherm with a hysteresis loop in the $\mathrm{P} / \mathrm{P}_{0}$ range of $0.25-1.0$, suggesting the materials have a mesoporous structure. These curves were based on the IUPAC classification of type IV isotherms with loop hysteresis. The specific surface area calculated for the nanocomposite created in the current density of $-6.0 \mathrm{~mA} / \mathrm{cm}^{2}$ were $40.2 \mathrm{~m}^{2} / \mathrm{g}$. The resulting structure had several advantages in electrochemical supercapacitors. Interconnected $\mathrm{NiCo}_{2} \mathrm{O}_{4}$ sheets grown directly on 


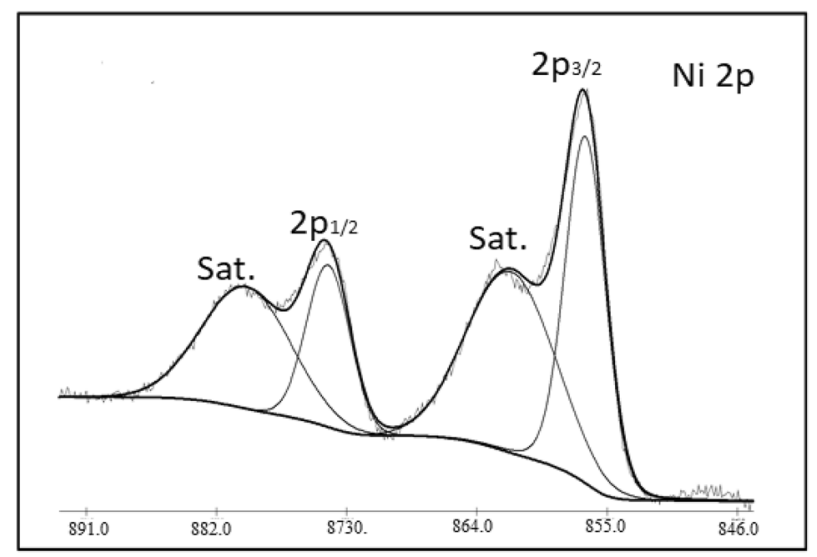

Binding Energy $[\mathrm{eV}]$

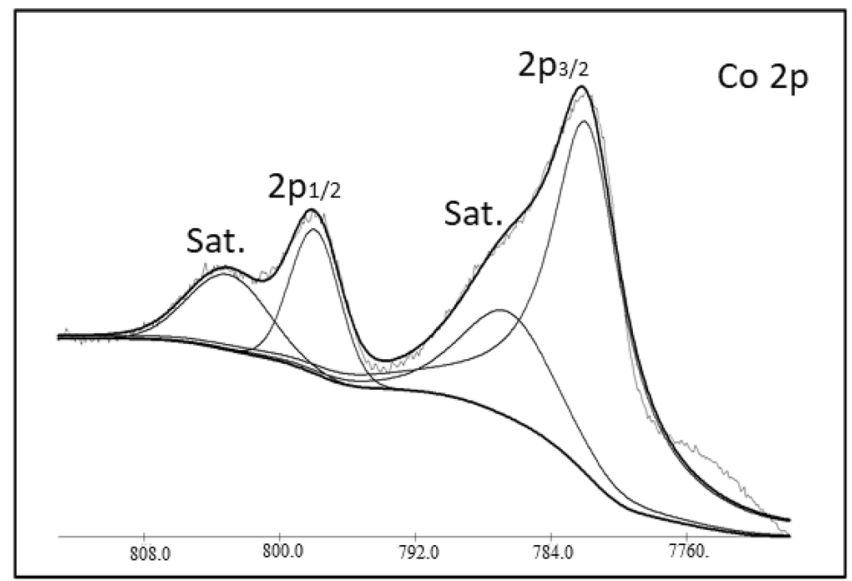

Binding Energy $[\mathrm{eV}]$

Figure 5. High-resolution XPS spectra of Ni 2p and Co 2p.

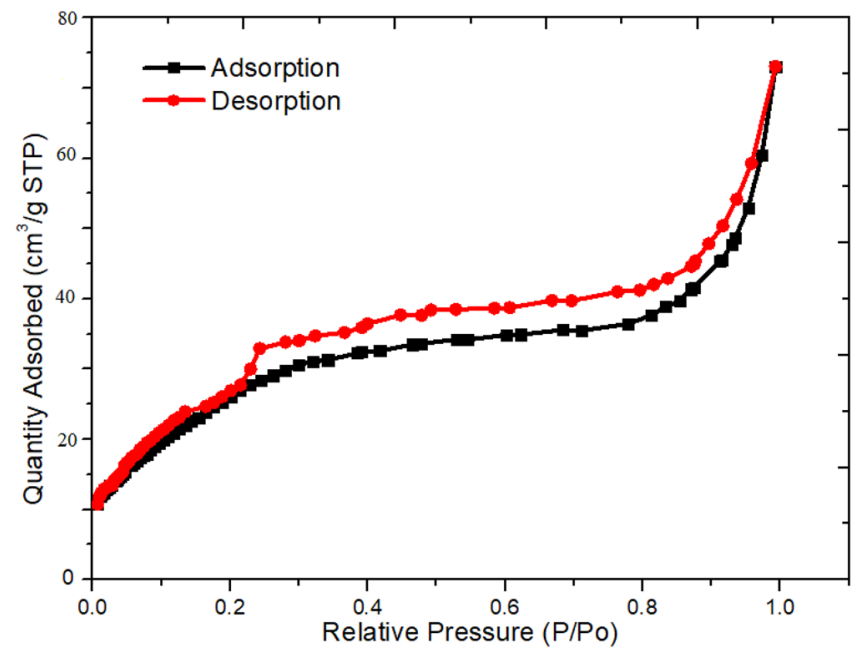

Figure 6. Nitrogen adsorption and desorption isotherms for the $\mathrm{NiCo}_{2} \mathrm{O}_{4}$ sheets. 
the nickel foam using electrochemical deposition method provided an integrated and orderly electrode that facilitated the transport of ion and electrons, thereby reducing the electrode resistance.

Figure 7 (a) shows the cyclic voltammetry $(\mathrm{CV})$ curves of $\mathrm{NiCo}_{2} \mathrm{O}_{4}$ with different numbers of electrodeposition cycles at $5 \mathrm{mV} \mathrm{s}^{-1}$. The $\mathrm{NiCo}_{2} \mathrm{O}_{4} \_1$ electrode demonstrates higher peak currents and larger integrated areas compared with the $\mathrm{NiCo}_{2} \mathrm{O}_{4-} 2, \mathrm{NiCo}_{2} \mathrm{O}_{4-} 4$, and $\mathrm{NiCo}_{2} \mathrm{O}_{4-} 6$ electrodes. Further, the properties of $\mathrm{NiCo}_{2} \mathrm{O}_{4}{ }_{-} 1$ shown in Fig. 7(b) indicate better electrochemical capacity than those of $\mathrm{Co}_{3} \mathrm{O}_{4}$ and $\mathrm{NiO}$. Figure $7(\mathrm{c})$ shows the $\mathrm{CV}$ curves of the $\mathrm{NiCo}_{2} \mathrm{O}_{4}$ electrode at scan rates from 5 to $100 \mathrm{mV} \mathrm{s}{ }^{-1}$ with a $0-0.6 \mathrm{~V}$ potential window (vs. $\mathrm{HgCl}$ reference electrode). Even at a relatively high scan rate, a couple of redox peaks are evident, a battery characteristic signifying quick kinetics ${ }^{16}$. The current response enhanced with increasing sweep rate without noticeable alteration in the trend of the CV curves. Furthermore, these peaks are attributed primarily to the faradaic redox reactions involving $\mathrm{M}-\mathrm{O}-\mathrm{OH} / \mathrm{M}-\mathrm{O}$ (where $\mathrm{M}$ signifies $\mathrm{Co}$ or $\mathrm{Ni})^{36}$. Figure $7(\mathrm{~d}, \mathrm{e})$ presents the galvanostatic charge-discharge (GCD) measurements of $\mathrm{Co}_{3} \mathrm{O}_{4}, \mathrm{NiO}$, and $\mathrm{NiCo}_{2} \mathrm{O}_{4} 1$ with different numbers of electrodeposition cycles at $2 \mathrm{~A} \mathrm{~g}^{-1}$ from 0 to $0.55 \mathrm{~V}$. Among the samples, $\mathrm{NiCo}_{2} \mathrm{O}_{4}-1$ had the best charge-discharge properties. The GCD curves at various CDs are demonstrated in Fig. 7 (f). These CD curves are nonlinear, indicating typical battery-type capacitive behaviour ${ }^{37,38}$. These results confirm that the $\mathrm{NiCo}_{2} \mathrm{O}_{4-1} 1$ electrode had a much higher specific capacitance than the $\mathrm{NiCo}_{2} \mathrm{O}_{4}$ electrodes with more deposition cycles. The remarkable electrochemical performance of the $\mathrm{NiCo}_{2} \mathrm{O}_{4} 1$ electrode could be attributed to the excellent adhesion to the nickel foam substrate, with a large surface area and electrical connection of the active material to the current collector to ensure effective accessibility of the electrolyte ions and electrons.

Equation 1 defines a numerical calculation of specific capacitance during current density characterization ${ }^{39}$ :

$$
C=\frac{I \Delta t}{m \Delta V}
$$

where $m, I, \Delta V, \Delta t$, and $C$ are the active materials mass, discharge current, drop in potential, total discharge time, and specific capacitance, respectively.

Figure 8 (a) shows the specific capacitance of $\mathrm{NiCo}_{2} \mathrm{O}_{4}$ with different numbers of electrodeposition cycles at different current densities. $\mathrm{NiCo}_{2} \mathrm{O}_{4-} 1$ shows a superior specific capacitance. Figure 8 (b) shows the specific capacitance of $\mathrm{NiCo}_{2} \mathrm{O}_{4-1} 1, \mathrm{NiO}$, and $\mathrm{Co}_{3} \mathrm{O}_{4}$, and the $\mathrm{NiCo}_{2} \mathrm{O}_{4-1} 1$ nanosheet electrode shows excellent capacitance values of $1734.9,1590.5,1514.7,1391.3,1302.4$, and $1201.8 \mathrm{~F} \mathrm{~g}^{-1}$ at CDs of 2, 6, 10, 20, 30, and $50 \mathrm{~A} \mathrm{~g}^{-1}$, respectively. This shows that when the charge-discharge rate increases from 2 to $50 \mathrm{~A} \mathrm{~g}^{-1}$, around $87.3 \%$ of the capacitance is retained.

Electrochemical impedance spectroscopy (EIS) tests were carried out to examine the ion transport properties of the synthesised materials in the $0.01 \mathrm{~Hz}-100 \mathrm{kHz}$ frequency range. Figure 9 shows the EIS results for the $\mathrm{NiCo}_{2} \mathrm{O}_{4} n\left(n=1,2,4\right.$, and 6), $\mathrm{NiO}$, and $\mathrm{Co}_{3} \mathrm{O}_{4}$ materials. The Nyquist plots of the electrodes contain straight and semicircular curves in the low and high frequency regions, respectively ${ }^{40-43}$. The intercept of $Z_{0}$ (the real axis) with the semicircle, in the high-frequency region, is identical to $R_{\mathrm{s}}$ (the internal resistance), which comprises of the ohmic resistance of the active materials, the resistance of the electrolyte, and the contact resistance at the interface of the active material/nickel foam. The internal resistance values of the $\mathrm{NiCo}_{2} \mathrm{O}_{4} 1, \mathrm{NiO}$, and $\mathrm{Co}_{3} \mathrm{O}_{4}$ electrodes were $0.35,0.22$, and $1.58 \Omega$, respectively. The semicircle represents $C_{\mathrm{dl}}$ (the double-layer capacitance), which is related to the surface properties of the electrode, and the semicircle diameter indicates $R_{\mathrm{ct}}$ (the charge transfer resistance), which is related to the corresponding faradaic reactions at the interface of the electrode-electrolyte. On the contrary, the slope of the curves in the low frequency region signifies the Warburg resistance, which is related to the diffusion of the electrolyte in the electrodes. It is known that the electrochemical performance of supercapacitors can be effectively enhanced by reducing this resistance. Based on the results of GCD, an extraordinary specific capacitance of $1734.5 \mathrm{~F} \mathrm{~g}^{-1}$ was obtained at a current density of $2 \mathrm{~A} \mathrm{~g}^{-1}$. The $\mathrm{CV}$ curves of $\mathrm{NiCo}_{2} \mathrm{O}_{4}$ with different numbers of electrodeposition cycles at $5 \mathrm{mV} \mathrm{s}^{-1}$ are given in Fig. 9(a). The $\mathrm{NiCo}_{2} \mathrm{O}_{4-} 1$ electrode demonstrates higher peak currents and larger integrated areas compared with the $\mathrm{NiCo}_{2} \mathrm{O}_{4} \_2, \mathrm{NiCo}_{2} \mathrm{O}_{4-} 4$, and $\mathrm{NiCo}_{2} \mathrm{O}_{4} 6$ electrodes. The internal resistance of the $\mathrm{NiCo}_{2} \mathrm{O}_{4} \_1$ electrode was only $0.35 \Omega$. These results indicate that $\mathrm{NiCO}_{2} \mathrm{O}_{4} \_1$ electrode has good electrochemical performance.

The cycle life performance of $\mathrm{NiCO}_{2} \mathrm{O}_{4}$ at a CD of $30 \mathrm{~A} \mathrm{~g}^{-1}$ for 3500 cycles is presented in Fig. 10. The $\mathrm{NiCo}_{2} \mathrm{O}_{4}$ deposited on the nickel foam electrode shows steady cycling stability. From the calculation for the discharge curves, an approximate decrease of only $12.7 \%$ in the specific capacitance value after 3500 cycles is obtained. At low current densities, some side reactions occurred during the electrochemical redox reaction, leading to incomplete discharge. As the current density increased, the charge and discharge time decreased. The electrochemical process was mainly affected by the electric double layer, so the Coulomb efficiency increased as well ${ }^{9}$. Given the superior electrochemical behaviour of the $\mathrm{NiCo}_{2} \mathrm{O}_{4}$ electrode, it is the best choice for use in electrochemical supercapacitors characterised by both excellent rate capability and long cycle life.

Furthermore, to study the practical performance of the synthesised electrode in this work, asymmetric supercapacitors (ASCs) were assembled, in which carbon nanotubes (CNTs) and $\mathrm{NiCo}_{2} \mathrm{O}_{4}$ were the cathode and anode, respectively, with a polyvinyl alcohol- $\mathrm{KOH}$ gel polymer electrolyte. Figure 11(a) displays the CV curves of the anode and cathode at 5-100 mV s${ }^{-1}$ scan rates. Figure $12(\mathrm{~b})$ indicates that the $\mathrm{NiCo}_{2} \mathrm{O}_{4}$ and $\mathrm{CNT}$ electrodes operate in voltage ranges of $0.0-0.6 \mathrm{~V}$ and -1.0 to $0.0 \mathrm{~V}$, respectively. Consequently, the $\mathrm{NiCo}_{2} \mathrm{O}_{4} / \mathrm{CNT}$ ASC can operate in a $1.6 \mathrm{~V}$ voltage range $\mathrm{e}^{12}$. As the scan rate increases from 5 to $100 \mathrm{mV} \mathrm{s}^{-1}$, the shape of the $\mathrm{CV}$ curve does not change, indicating that the device has good and rapid charge-discharge properties. The charge-discharge behaviour of the device is depicted in Fig. 11(b). These charge-discharge curves are nonlinear, indicating battery-type capacitive behaviour. Equations 2 and 3 were used to further investigate the excellent rate capability and high capacitance to evaluate the performance indicators of specific power density $(P)$ and specific energy density $(E)$ from the discharge curves ${ }^{13,44-47}$. 

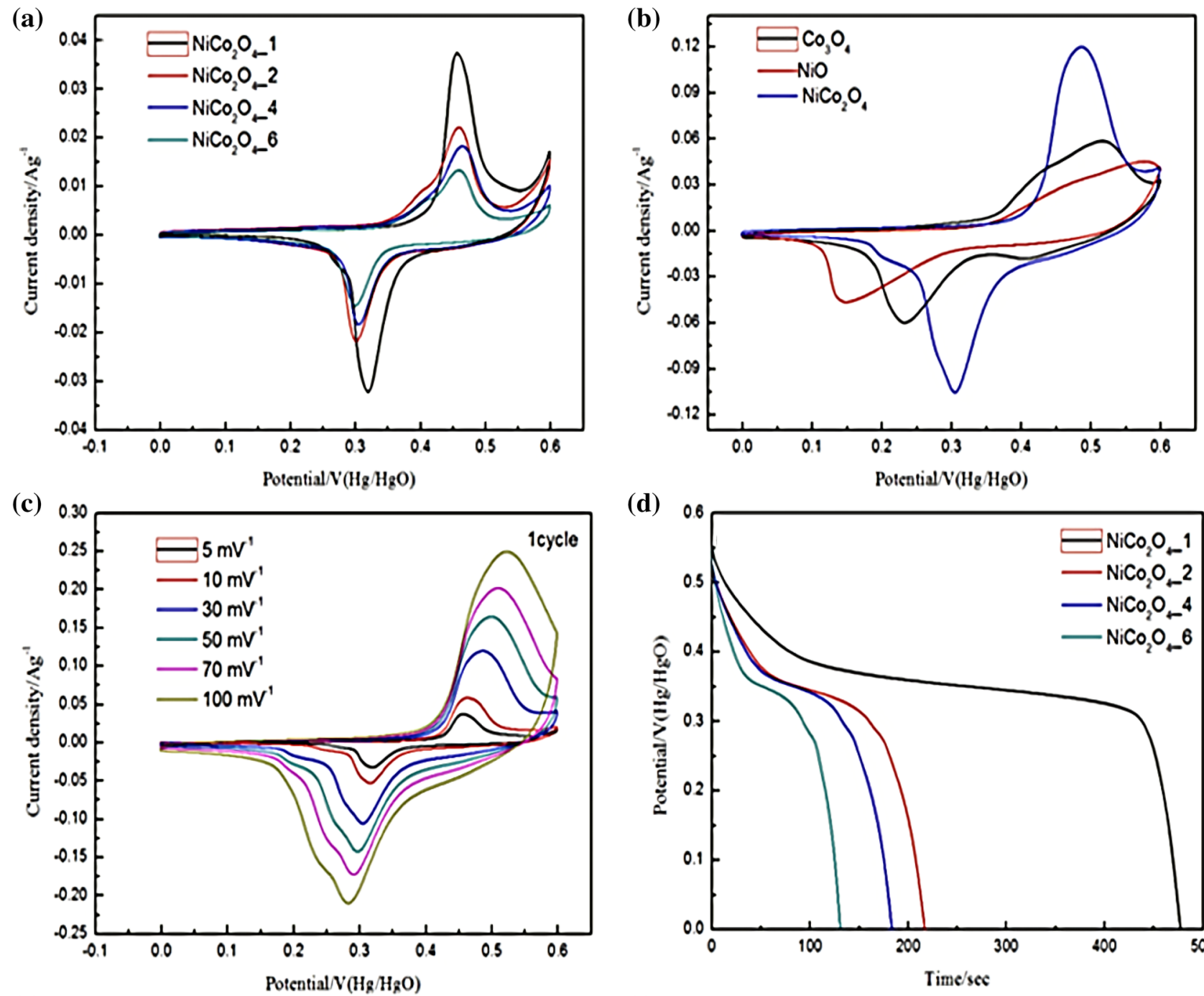

(d)
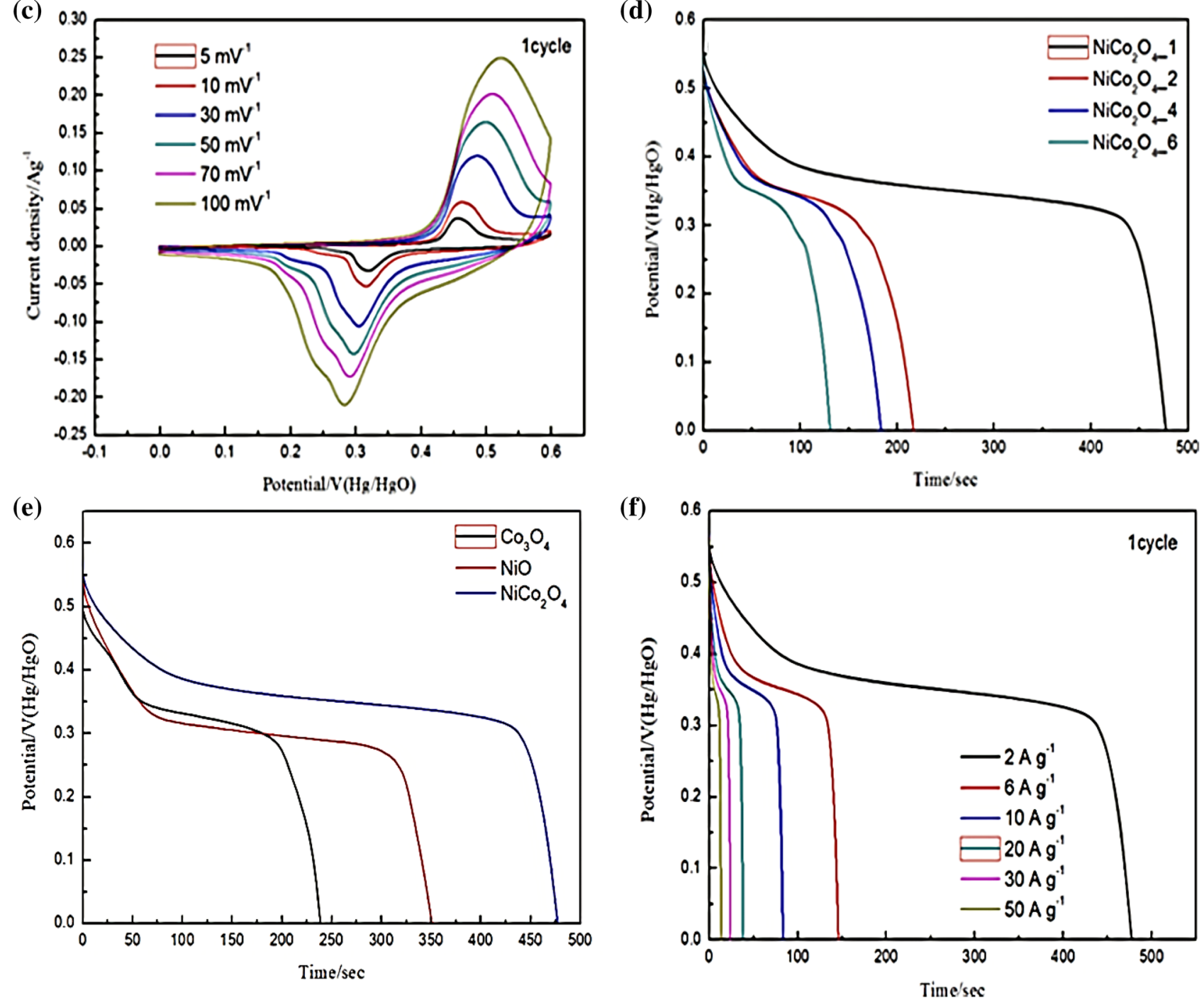

Figure 7. $\mathrm{CV}$ curves of (a) $\mathrm{NiCo}_{2} \mathrm{O}_{4}$ with different numbers of electrodeposition cycles at $5 \mathrm{mV} \mathrm{s}^{-1}$; (b) $\mathrm{NiCo}_{2} \mathrm{O}_{4}, \mathrm{Co}_{3} \mathrm{O}_{4}$, and $\mathrm{NiO}$ as the electrode material at $30 \mathrm{mV} \mathrm{s}^{-1}$; and (c) $\mathrm{NiCo}_{2} \mathrm{O}_{4}$ at different scan rates. GCD curves of (d) $\mathrm{NiCo}_{2} \mathrm{O}_{4}$ with different numbers of electrodeposition cycles at $2 \mathrm{~A} \mathrm{~g}^{-1}$; (e) $\mathrm{NiCo}_{2} \mathrm{O}_{4}, \mathrm{Co}_{3} \mathrm{O}_{4}$, and $\mathrm{NiO}$ as the electrode material at $2 \mathrm{~A} \mathrm{~g}^{-1}$, and (f) $\mathrm{NiCo}_{2} \mathrm{O}_{4}$ at different CDs. 

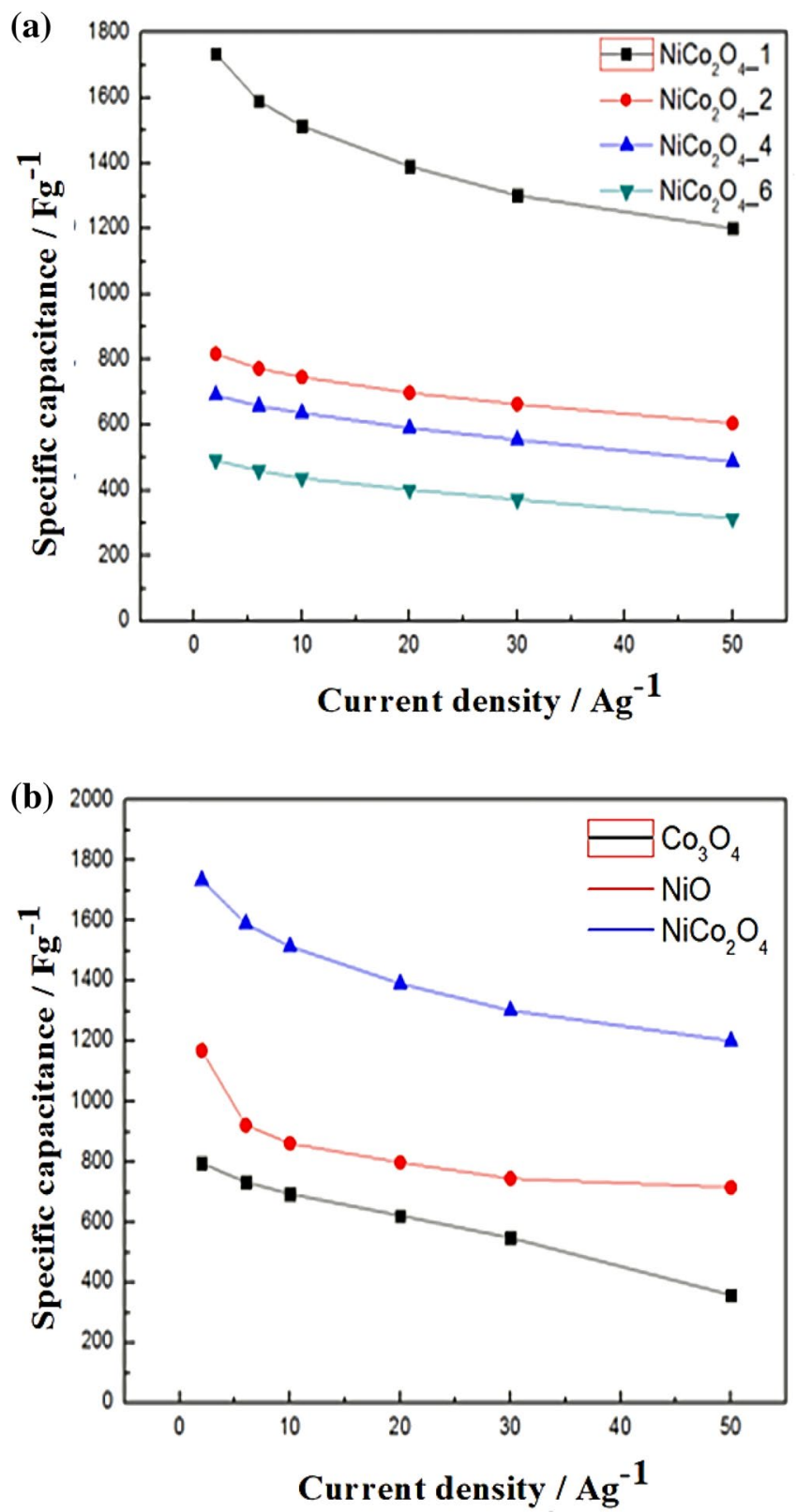

Figure 8. (a) Specific capacitance of $\mathrm{NiCo}_{2} \mathrm{O}_{4}$ with different numbers of electrodeposition cycles at different CDs. (b) Specific capacitance of $\mathrm{NiCo}_{2} \mathrm{O}_{4-1}, \mathrm{NiO}$, and $\mathrm{Co}_{3} \mathrm{O}_{4}$ at different CDs.

$$
\begin{gathered}
E=1 / 2\left(C \times \Delta V^{2}\right) \\
P=3600(E / \Delta t)
\end{gathered}
$$

where $\Delta V, C$, and $\Delta t$ are the potential drop during discharge, specific capacitance derived from the charge-discharge calculations, and full discharge duration, respectively.

Figure 12 depicts the power and energy density plot (Ragone plot) of the devices at different charge-discharge rates. The calculated energy densities of the $\mathrm{NiCo}_{2} \mathrm{O}_{4} / \mathrm{CNT}$ ASC were 42.25, 41.43, 29.25, 23.73, and $19.16 \mathrm{~W} \mathrm{~h} \mathrm{~kg}^{-} 1$ at power densities of $298.79,596.66,1196.52,2966.29$, and $5796.04 \mathrm{~W} \mathrm{~kg}^{-1}$, respectively. These findings indicate that the ASC device attained a greater energy density than reported devices, such as colloidal quantum dots $/ \mathrm{NiCo}_{2} \mathrm{O}_{4} /$ activated carbon (AC) $\left(27.8 \mathrm{~W} \mathrm{~h} \mathrm{~kg}-1 \text { at } 128 \mathrm{~W} \mathrm{~kg}^{-1}\right)^{48,49}, \mathrm{NiCo}_{2} \mathrm{O}_{4}$-reduced graphene oxide/AC $\left(23.32 \mathrm{~W} \mathrm{~h} \mathrm{~kg}{ }^{-1} \text { at } 324.9 \mathrm{~kW} \mathrm{~kg}^{-1}\right)^{50}, \mathrm{Ni}_{\mathrm{x}} \mathrm{Co}_{1-\mathrm{x}} \mathrm{LDH}-\mathrm{zinc}$ tin oxide/AC $\left(23.7 \mathrm{~W} \mathrm{~h} \mathrm{~kg}^{-1}\right.$ at $\left.284.2 \mathrm{~W} \mathrm{~kg}^{-1}\right)^{51}$, and CoO@polypyrrole/AC $\left(43.5 \mathrm{~W} \mathrm{~h} \mathrm{~kg}^{-1} \text { at } 87.5 \mathrm{~W} \mathrm{~kg}^{-1}\right)^{52}$. 

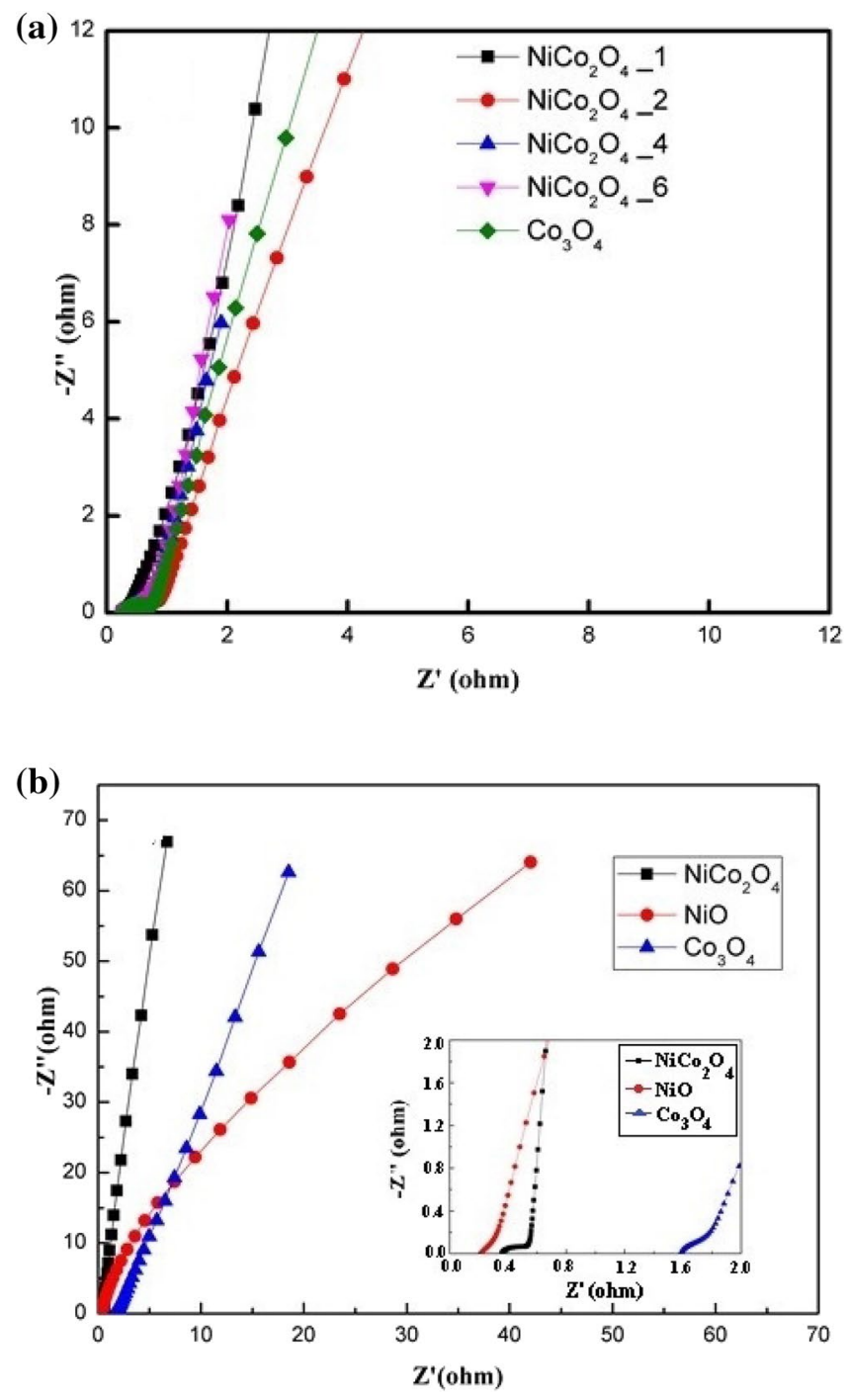

Figure 9. Nyquist impedance plots of (a) $\mathrm{NiCo}_{2} \mathrm{O}_{4}$ with different numbers of deposition cycles and (b) $\mathrm{NiCo}_{2} \mathrm{O}_{4}, \mathrm{NiO}$, and $\mathrm{Co}_{3} \mathrm{O}_{4}$.

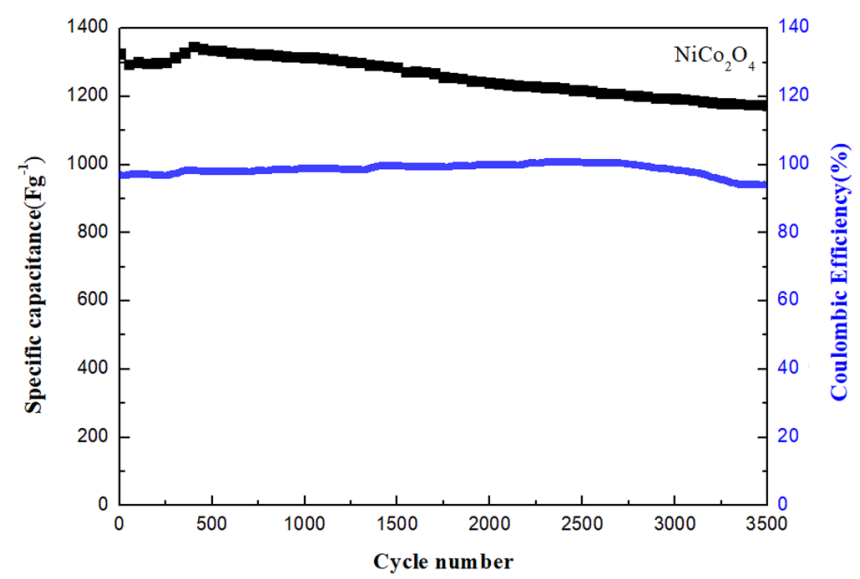

Figure 10. Cycling stability and Coulombic efficiency of the $\mathrm{NiCo}_{2} \mathrm{O}_{4}$ electrode at a $\mathrm{CD}$ of $30 \mathrm{~A} \mathrm{~g}^{-1}$ for 3500 cycles. 

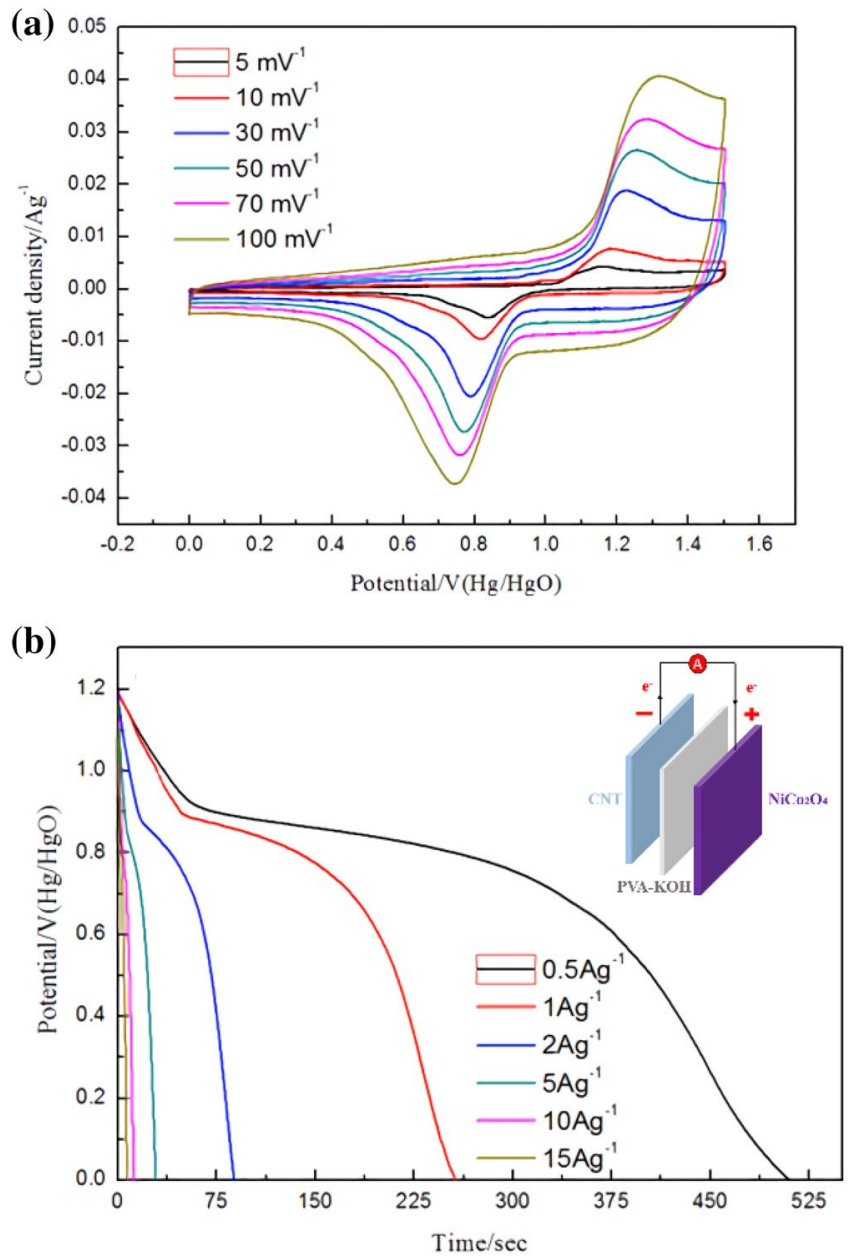

Figure 11. (a) CV curves of the ASC device. (b) Charge-discharge curves of the ASC device. The embedded picture is a schematic of the ASC device.

\section{Conclusions}

In summary, $\mathrm{NiCo}_{2} \mathrm{O}_{4}$ was synthesised on nickel foam via electrodeposition. $\mathrm{NiCo}_{2} \mathrm{O}_{4}$ was found to have superior specific capacitances of 1734.9 and $1201.8 \mathrm{~F} \mathrm{~g}^{-1}$ at CDs of 2 and $50 \mathrm{~A} \mathrm{~g}^{-1}$, respectively, with great cycling stability (only 12.7\% loss after 3500 cycles). Furthermore, a high performance solid-state ASC was built utilising $\mathrm{NiCo}_{2} \mathrm{O}_{4}$ and CNTs as the anode and cathode, respectively, and the solid-state polyvinyl alcohol-KOH gel as an electrolyte. A specific capacitance of $212.47 \mathrm{~F} \mathrm{~g}^{-1}$ was attained at a $0.5 \mathrm{~A} \mathrm{~g}^{-1} \mathrm{CD}$. Moreover, the ASC exhibited a high energy density $\left(42.25 \mathrm{~W} \mathrm{~h} \mathrm{~kg}^{-1}\right)$ at a $298.79 \mathrm{~W} \mathrm{~kg}^{-1}$ power density and a high power density $\left(5,796.04 \mathrm{~W} \mathrm{~kg}^{-1}\right)$ at a $19.16 \mathrm{~W} \mathrm{~h} \mathrm{~kg}^{-1}$ energy density.

\section{Materials and methods}

Preparation of nickel cobaltite. The electrochemical deposition was carried out at ambient temperature to synthesize $\mathrm{NiCO}_{2} \mathrm{O}_{4}$ nanosheets onto nickel foam in a 3-electrode cell in which nickel foam, saturated calomel, and $\mathrm{Pt}$ foil utilized as working, reference, and counter electrodes, respectively. Nickel-Cobalt layered double hydroxide precursor was deposited over nickel foam in an aqueous mixed electrolyte of $2 \mathrm{mM}$ cobalt nitrate and $1 \mathrm{mM}$ nickel nitrate using a ZIVE SP2 electrochemical workstation.

Versatile numbers of cycles like 1,2, 4, and 6 cycles were selected for electrodeposition of working electrodes with the potential of $-1.2-0.5 \mathrm{~V}$ (vs. SCE). The nickel foams were ultrasonically cleaned and rinsed three times with distilled water and ethanol after electrodeposition and then dried at ambient temperature. Then, the electrodeposited working electrodes was placed in a muffle furnace and annealed for two hours at $300{ }^{\circ} \mathrm{C}$, to transform the coating into interconnected mesoporous $\mathrm{NiCo}_{2} \mathrm{O}_{4}$ nanosheets; it was carefully weighed after annealing (Fig. 1). The obtained $\mathrm{NiCo}_{2} \mathrm{O}_{4}$ specimens are called as $\mathrm{NiCo}_{2} \mathrm{O}_{4} n$ (where $n$ is the number of cycles, $n=1,2,4$, and 6), and henceforth " $\mathrm{NiCo}_{2} \mathrm{O}_{4}$ " denotes the $n=1$ sample when $\mathrm{NiCo}_{2} \mathrm{O}_{4}$ is compared with other materials.

Preparation of flexible solid electrolyte. The solution-casting technique was used to prepare the potassium hydroxide and PVA polymer electrolyte. $2 \mathrm{~g}$ of polyvinyl alcohol was added into $30 \mathrm{ml}$ of double-distilled 
(a)
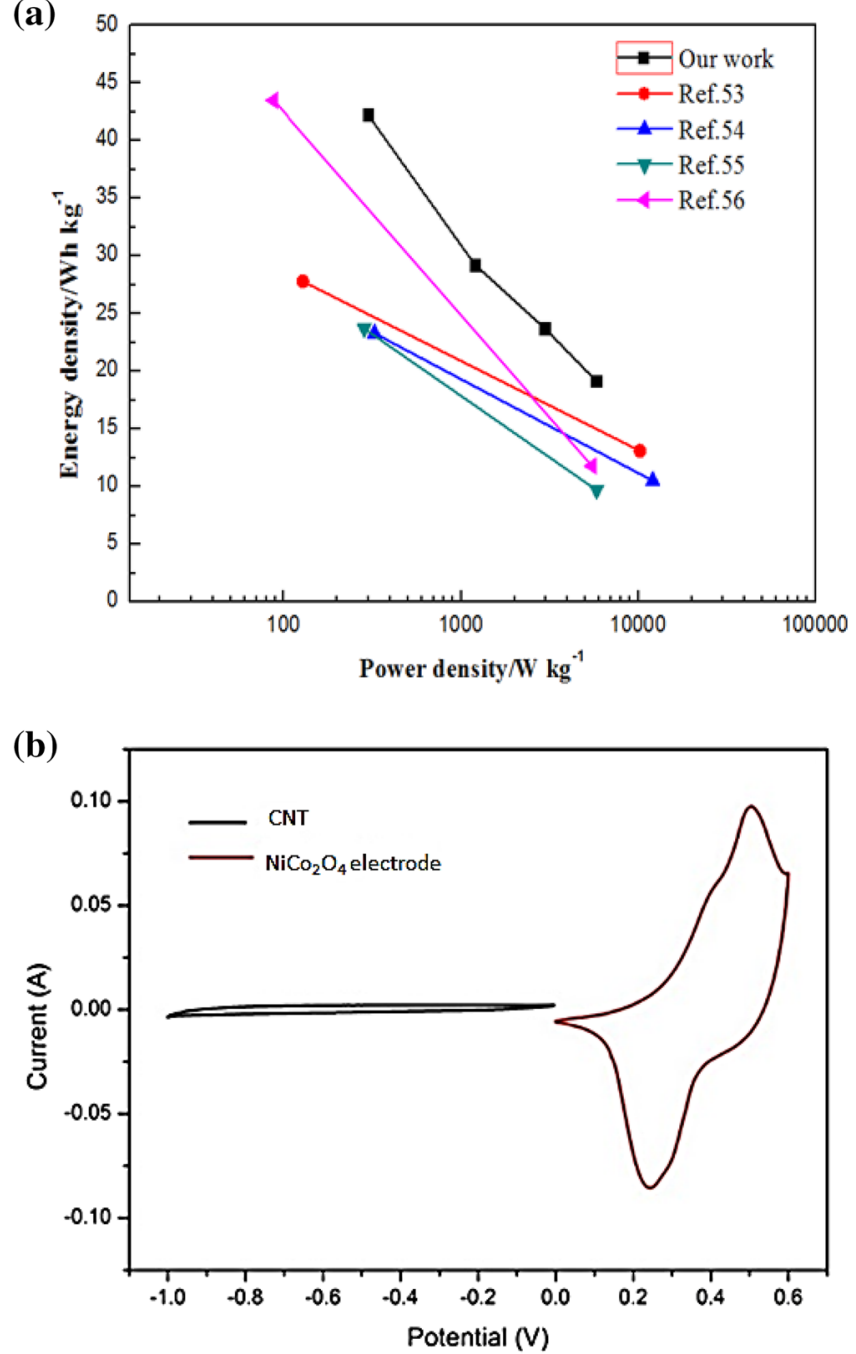

Figure 12. (a) Power and energy density plot (Ragone plot) of the current ASC device at different chargedischarge rates compared with the literature. (b) CV curves of the $\mathrm{CNT}$ and $\mathrm{NiCo}_{2} \mathrm{O}_{4}$ electrodes in a threeelectrode system at a scan rate of $5 \mathrm{mV} \mathrm{s}^{-1}$.

water and stirred for three hours at $80^{\circ} \mathrm{C}$. Then $6 \mathrm{M}$ potassium hydroxide was mixed the prepared solution with agitation at room temperature for $3 \mathrm{~h}$. After dissolution was complete, the final mixture was constantly agitated until a homogeneous viscous product was obtained. Finally, to attain a jelly electrolyte, the mixture was transferred to an oven (vacuum) and kept at $70^{\circ} \mathrm{C}$ overnight.

Characterization of $\mathrm{NiCO}_{2} \mathrm{O}_{4}$. The morphology and microstructure of specimens were examined by FESEM (FESEM, LEO-1550) equipped with EDS at a $5 \mathrm{kV}$ applied voltage. XRD tests were carried out (Bruker D8 Advance X-ray diffractometer) with $\mathrm{Cu} \mathrm{K}-\alpha$ radiation $(\lambda=0.154056 \mathrm{~nm})$ at $30 \mathrm{~mA}$ and $40 \mathrm{kV}$. The speed of scanning was $5^{\circ} \mathrm{min}^{-1}$ with $0.02^{\circ}$ steps. Elemental mapping (FEI Talos microscope operating at a $200 \mathrm{kV}$ accelerating voltage), high-angle annular dark-field scanning, and TEM (HAADF-STEM-EDS) were used to characterize the specimens. Thermo VG Escalab 250 photoelectron spectrometer was used for XPS analysis. The pore structures were evaluated by $\mathrm{N}^{2}$ adsorption at 77 Kusing volumetric equipment (Quantachrome AS-1-MP) after pre-evacuation for $2 \mathrm{~h}$ at $423 \mathrm{~K}$ while maintaining a base pressure of $10^{-4} \mathrm{~Pa}$.

Electrochemical characterizations. The electrochemical characterizations containing electrochemical impedance spectroscopy (EIS), galvanostatic charge-discharge (GCD), and cyclic voltammetry (CV) were carried out in a conventional three-electrode configuration at ambient temperature in which the $\mathrm{NiCo}_{2} \mathrm{O}_{4}$ on $\mathrm{Ni}$ foam electrode was utilized as the working electrode, and a $\mathrm{Hg} / \mathrm{HgO}$ and $\mathrm{Pt}$ foil were the reference and counter electrodes. The electrochemical characterizations were done using a $6 \mathrm{M}$ potassium hydroxide solution with the aid of ZIVE SP2 workstation $(10 \mu \mathrm{Hz}-4 \mathrm{MHz})$. The voltage range was from 0 to $0.6 \mathrm{~V} \mathrm{vs.} \mathrm{Hg} / \mathrm{HgO}$ for the $\mathrm{NiCo}_{2} \mathrm{O}_{4}$ electrode. To examine the energy storage performance of the working electrode for practical applica- 
tion, the anode electrode material was nickel cobalt oxide, and the cathode electrode material was carbon nanotubes (CNTs). The voltage range was from 0 to $1.5 \mathrm{~V}$ vs. $\mathrm{Hg} / \mathrm{HgO}$ for the $\mathrm{CNT}$ electrode.

Received: 17 November 2019; Accepted: 10 September 2020

Published online: 03 November 2020

\section{References}

1. Choi, H. J. et al. Graphene for energy conversion and storage in fuel cells and supercapacitors. Nano Energy 4, 534-551 (2012).

2. Qiu, K. et al. Mesoporous, hierarchical core/shell structured $\mathrm{ZnCo}_{2} \mathrm{O}_{4} / \mathrm{MnO}_{2}$ nanocone forests for high-performance supercapacitors. Nano Energy 11, 687-696 (2015).

3. Dubal, D. P., Ayyad, O., Ruiz, V. \& Gomez-Romero, P. Hybrid energy storage: The merging of battery and supercapacitor chemistries. Chem. Soc. Rev. 44, 1777-1790 (2015).

4. Puthusseri, D., Aravindan, V., Madhavi, S. \& Ogale, S. 3D micro-porous conducting carbon beehive by single step polymer carbonization for high performance supercapacitors: The magic of in situ porogen formation. Energ. Environ. Sci. 7, 728-735 (2014).

5. Lu, X. et al. High energy density asymmetric quasi-solid-state supercapacitor based on porous vanadium nitride nanowire anode. Nano Lett. 13, 2628-2633 (2013).

6. Largeot, C. et al. Relation between the ion size and pore size for an electric double-layer capacitor. J. Am. Chem. Soc. 130, 2730-2731 (2008).

7. Kandalkar, S., Dhawale, D., Kim, C. K. \& Lokhande, C. Chemical synthesis of cobalt oxide thin film electrode for supercapacitor application. Synth. Metals 160, 1299-1302 (2010).

8. Wang, C., Sun, P., Qu, G., Yin, J. \& Xu, X. Nickel/cobalt based materials for supercapacitors. Chin. Chem. Lett. 29, 1731-1740 (2018).

9. Wang, C. et al. $\mathrm{NiCo}(2) \mathrm{O}(4)$-Based Supercapacitor Nanomaterials. Nanomaterials-Basel 7, 1-23 (2017).

10. Wu, H. B., Pang, H. \& Lou, X. W. D. Facile synthesis of mesoporous Ni0.3 $\mathrm{Co}_{2.7} \mathrm{O}_{4}$ hierarchical structures for high-performance supercapacitors. Energ. Environ. Sci. 6, 3619-3626 (2013).

11. Yuan, C. et al. Ultrathin mesoporous $\mathrm{NiCo}_{2} \mathrm{O}_{4}$ nanosheets supported on $\mathrm{Ni}$ foam as advanced electrodes for supercapacitors. $A d v$. Funct. Mater. 22, 4592-4597 (2012).

12. Shen, L., Yu, L., Yu, X. Y., Zhang, X. \& Lou, X. W. Self-templated formation of uniform $\mathrm{NiCo}_{2} \mathrm{O}_{4}$ hollow spheres with complex interior structures for lithium-ion batteries and supercapacitors. Angew. Chem. Int. Edit. 54, 1868-1872 (2015).

13. Li, H. et al. Electrodeposited NiCo layered double hydroxides on titanium carbide as a binder-free electrode for supercapacitors. Electrochim. Acta 261, 178-187 (2018).

14. Kim, J. G., Pugmire, D., Battaglia, D. \& Langell, M. Analysis of the $\mathrm{NiCo}_{2} \mathrm{O}_{4}$ spinel surface with Auger and X-ray photoelectron spectroscopy. Appl. Surf. Sci. 165, 70-84 (2000).

15. Chen, X. et al. Electrodeposited nickel aluminum-layered double hydroxide on $\mathrm{Co}_{3} \mathrm{O}_{4}$ as binder-free electrode for supercapacitor. J. Mater. Sci. Mater. Electron. 30, 2419-2430 (2019).

16. Wu, P. et al. A low-cost, self-standing $\mathrm{NiCo}_{2} \mathrm{O}_{4} @ \mathrm{CNT} / \mathrm{CNT}$ multilayer electrode for flexible asymmetric solid-state supercapacitors. Adv. Funct. Mater. 27, 1702160 (2017).

17. Li, Y., Tang, F., Wang, R., Wang, C. \& Liu, J. Novel dual-ion hybrid supercapacitor based on a NiCo2O4 nanowire cathode and MoO2-C nanofilm anode. ACS Appl. Mater. Inter. 8, 30232-30238 (2016).

18. Wang, N. et al. Electrodeposition preparation of $\mathrm{NiCo}_{2} \mathrm{O}_{4}$ mesoporous film on ultrafine nickel wire for flexible asymmetric supercapacitors. Chem. Eng. J. 345, 31-38 (2018).

19. Liu, Y. et al. Molecular design of mesoporous $\mathrm{NiCo}_{2} \mathrm{O}_{4}$ and $\mathrm{NiCo}_{2} \mathrm{~S}_{4}$ with sub-micrometer-polyhedron architectures for efficient pseudocapacitive energy storage. Adv. Funct. Mater. 27, 1701229 (2017).

20. Huang, Y. Y. et al. Graphene quantum dots-induced morphological changes in $\mathrm{CuCo}_{2} \mathrm{~S}_{4}$ nanocomposites for supercapacitor electrodes with enhanced performance. Appl. Surf. Sci. 463, 498-503 (2019).

21. Dong, Y., He, K., Yin, L. \& Zhang, A. A facile route to controlled synthesis of $\mathrm{Co}_{3} \mathrm{O}_{4}$ nanoparticles and their environmental catalytic properties. Nanotechnology 18, 435602 (2007).

22. Xu, J. M., Wang, X. C. \& Cheng, J. P. Supercapacitive performances of ternary $\mathrm{CuCo}_{2} \mathrm{~S}_{4}$ sulfides. ACS Omega 5, 1305-1311 (2020).

23. Zangari, G. Electrodeposition of alloys and compounds in the era of microelectronics and energy conversion technology. Coatings 5, 195-218 (2015).

24. Chen, W., Xia, C. \& Alshareef, H. N. One-step electrodeposited nickel cobalt sulfide nanosheet arrays for high-performance asymmetric supercapacitors. ACS Nano 8, 9531-9541 (2014).

25. Wang, X. et al. Fiber-based flexible all-solid-state asymmetric supercapacitors for integrated photodetecting system. Angew. Chem. 126, 1880-1884 (2014).

26. Sennu, P., Aravindan, V. \& Lee, Y. S. High energy asymmetric supercapacitor with 1D@2D structured $\mathrm{NiCo}_{2} \mathrm{O}_{4} @ \mathrm{Co}_{3} \mathrm{O}_{4}$ and jackfruit derived high surface area porous carbon. J. Power Sources 306, 248-257 (2016).

27. Zhao, J., Li, Z., Zhang, M., Meng, A. \& Li, Q. Direct growth of ultrathin $\mathrm{NiCo}_{2} \mathrm{O}_{4} / \mathrm{NiO}$ nanosheets on $\mathrm{SiC}$ nanowires as a freestanding advanced electrode for high-performance asymmetric supercapacitors. ACS Sustain. Chem. Eng. 4, 3598-3608 (2016).

28. Yedluri, A., Araveeti, E. \& Kim, H. J. Facilely synthesized $\mathrm{NiCo}_{2} \mathrm{O}_{4} / \mathrm{NiCo}_{2} \mathrm{O}_{4}$ nanofile arrays supported on nickel foam by a hydrothermal method and their excellent performance for high-rate supercapacitance. Energies 12, 1308 (2019).

29. Yedluri, A. K. \& Kim, H.-J. Wearable super-high specific performance supercapacitors using a honeycomb with folded silk-like composite of $\mathrm{NiCo}_{2} \mathrm{O}_{4}$ nanoplates decorated with $\mathrm{NiMoO}_{4}$ honeycombs on nickel foam. Dalton Trans. 47, 15545 (2018).

30. Yedluri, A. K. \& Kim, H.-J. Preparation and electrochemical performance of $\mathrm{NiCo}_{2} \mathrm{O}_{4} @ \mathrm{NiCo}_{2} \mathrm{O}_{4}$ composite nanoplates for high performance supercapacitor applications. New J. Chem. 42, 19971 (2018).

31. Fan, Z. et al. Asymmetric supercapacitors based on graphene/ $\mathrm{MnO}_{2}$ and activated carbon nanofiber electrodes with high power and energy density. Adv. Funct. Mater. 21, 2366-2375 (2011).

32. Huang, L. et al. Nickel-cobalt hydroxide nanosheets coated on $\mathrm{NiCo}_{2} \mathrm{O}_{4}$ nanowires grown on carbon fiber paper for high-performance pseudocapacitors. Nano Lett. 13, 3135-3139 (2013).

33. Yan, J. et al. Advanced asymmetric supercapacitors based on $\mathrm{Ni}(\mathrm{OH})_{2} /$ graphene and porous graphene electrodes with high energy density. Adv. Funct. Mater. 22, 2632-2641 (2012).

34. Leng, X. et al. Ultrathin mesoporous $\mathrm{NiCo}_{2} \mathrm{O}_{4}$ nanosheet networks as high-performance anodes for lithium storage. ChemPlusChem 80, 1725-1731 (2015).

35. Mo, Y. et al. Three-dimensional $\mathrm{NiCo}_{2} \mathrm{O}_{4}$ nanowire arrays: preparation and storage behavior for flexible lithium-ion and sodiumion batteries with improved electrochemical performance. J. Mater. Chem. A 3, 19765-19773 (2015).

36. Wang, H., Gao, Q. \& Jiang, L. Facile approach to prepare nickel cobaltite nanowire materials for supercapacitors. Small 7, 2454-2459 (2011).

37. Jiang, S. et al. A facile enhancement in battery-type of capacitive performance of spinel $\mathrm{NiCo}_{2} \mathrm{O}_{4}$ nanostructure via directly tuning thermal decomposition temperature. Electrochim. Acta 191, 364-374 (2016).

38. Lin, X. et al. Synthesis and characterization of cobalt hydroxide carbonate nanostructures. RSC Adv. 7(74), 46925-46931 (2017). 
39. Singh, A. K., Sarkar, D., Khan, G. G. \& Mandal, K. Unique hydrogenated Ni/NiO core/shell 1D nano-heterostructures with superior electrochemical performance as supercapacitors. J. Mater. Chem. A 1, 12759-12767 (2013).

40. Liu, S. et al. Facile synthesis of microsphere copper cobalt carbonate hydroxides electrode for asymmetric supercapacitor. Electrochim. Acta 188, 898-908 (2016).

41. Xin, C. et al. Supercapacitor performance of nickel-cobalt sulfide nanotubes decorated using Ni Co-layered double hydroxide nanosheets grown in Situ on Ni foam. Nanomaterials 10(3), 584 (2020).

42. Zhang, L., Hui, K. N., Hui, K. S. \& Lee, H. Facile synthesis of porous CoAl-layered double hydroxide/graphene composite with enhanced capacitive performance for supercapacitors. Electrochim. Acta 186, 522-529 (2015).

43. Zhou, Q. et al. High rate capabilities of $\mathrm{NiCo}_{2} \mathrm{O}_{4}$-based hierarchical superstructures for rechargeable charge storage. J. Electrochem. Soc. 161, A1922-A1926 (2014).

44. Wang, Q. et al. Flexible coaxial-type fiber supercapacitor based on $\mathrm{NiCo}_{2} \mathrm{O}_{4}$ nanosheets electrodes. Nano Energy 8, 44-51 (2014).

45. Chen, X. Electrodeposited nickel aluminum-layered double hydroxide on $\mathrm{Co}_{3} \mathrm{O}_{4}$ as binder-free electrode for supercapacitor. $J$. Matter 30(3), 2419-2430 (2019).

46. Li, H. 3D hierarchical transition-metal sulfides deposited on MXene as binder-free electrode for high-performance supercapacitors. J. Ind. Eng. Chem. 82, 309-316 (2020).

47. Umeshbabu, E., Rajeshkhanna, G. \& Rao, G. R. Urchin and sheaf-like $\mathrm{NiCo}_{2} \mathrm{O}_{4}$ nanostructures: Synthesis and electrochemical energy storage application. Int. J. Hydrogen Energ. 39, 15627-15638 (2014).

48. Zhu, Y. et al. Porous $\mathrm{NiCo}_{2} \mathrm{O}_{4}$ spheres tuned through carbon quantum dots utilised as advanced materials for an asymmetric supercapacitor. J. Mater. Chem. A 3, 866-877 (2015).

49. Wang, X., Liu, W. S., Lu, X. \& Lee, P. S. Dodecyl sulfate-induced fast faradic process in nickel cobalt oxide-reduced graphite oxide composite material and its application for asymmetric supercapacitor device. J. Mater. Chem. 22, 23114-23119 (2012).

50. Wang, X., Sumboja, A., Lin, M., Yan, J. \& Lee, P. S. Enhancing electrochemical reaction sites in nickel-cobalt layered double hydroxides on zinc tin oxide nanowires: A hybrid material for an asymmetric supercapacitor device. Nanoscale 4, 7266-7272 (2012).

51. Zhou, C., Zhang, Y., Li, Y. \& Liu, J. Construction of high-capacitance 3D CoO@ polypyrrole nanowire array electrode for aqueous asymmetric supercapacitor. Nano Lett. 13, 2078-2085 (2013).

52. Chen, X. et al. Electrodeposited nickel aluminum-layered double hydroxide on $\mathrm{Co}_{3} \mathrm{O}_{4}$ as binder-free electrode for supercapacitor. J. Mater. Sci.: Mater. Electron. 30, 2419-2430 (2019).

\section{Acknowledgements}

This work was supported by the National Research Foundation of Korea (NRF) grant funded by the Korea government (MSIT) (No. NRF-2020R1A4A1019074). This work was funded by the Science and Technology Development Fund, Macau SAR (File no. 0191/2017/A3, 0041/2019/A1, 0046/2019/AFJ, 0021/2019/AIR), University of Macau (File no. MYRG2017-00216-FST and MYRG2018-00192-IAPME).

\section{Author contributions}

R.X., X.C., L.H. conceived the main idea. F.M., F.J., E.Z., S.B., K.S.H., and K.N.H. performed all the calculation work. All authors analyzed the results and wrote the paper.

\section{Competing interests}

The authors declare no competing interests.

\section{Additional information}

Correspondence and requests for materials should be addressed to E.Z. or S.B.

Reprints and permissions information is available at www.nature.com/reprints.

Publisher's note Springer Nature remains neutral with regard to jurisdictional claims in published maps and institutional affiliations.

(c) (i) Open Access This article is licensed under a Creative Commons Attribution 4.0 International License, which permits use, sharing, adaptation, distribution and reproduction in any medium or format, as long as you give appropriate credit to the original author(s) and the source, provide a link to the Creative Commons licence, and indicate if changes were made. The images or other third party material in this article are included in the article's Creative Commons licence, unless indicated otherwise in a credit line to the material. If material is not included in the article's Creative Commons licence and your intended use is not permitted by statutory regulation or exceeds the permitted use, you will need to obtain permission directly from the copyright holder. To view a copy of this licence, visit http://creativecommons.org/licenses/by/4.0/.

(c) The Author(s) 2020 